\title{
Same-turn self-repairs in Farsi conversation : On their initiation and framing
}

Kazemi, Ali

2020-12

Kazemi , A 2020 , ' Same-turn self-repairs in Farsi conversation : On their initiation and framing ' , Journal of Pragmatics , vol. 170 , pp. 4-19 . https://doi.org/10.1016/j.pragma.2020.08.004

http://hdl.handle.net/10138/333703

https://doi.org/10.1016/j.pragma.2020.08.004

cc_by_nc_nd

acceptedVersion

Downloaded from Helda, University of Helsinki institutional repository.

This is an electronic reprint of the original article.

This reprint may differ from the original in pagination and typographic detail.

Please cite the original version. 


\title{
Same-Turn Self-Repairs in Farsi Conversation: On their Initiation and Framing
}

\author{
Ali Kazemi, Department of Finnish, Finno-Ugrian \& Scandinavian Studies, University of \\ Helsinki, Helsinki, Finland
}

This study presents an account of the initiation and framing of self-initiated self-repairs in ongoing turn-constructional units in Farsi conversation. Informed by conversation analysis, the analysis of 636 instances of self-repairs culled from three data sources representing a wide variety of interactions revealed that there is some language-specific prosodic patterning which applies to both the foregrounding for incipient repairs and repair solutions. The particle yani (I mean, meaning), predominantly used as a pre-positioned lexical initiator, is routinely used to index a rather specific repair operation: substituting a wholly or partially uttered element of the current turn or repackaging the terms in which it has been couched. Unlike lexical initiators which are infrequent, retracting is frequently launched to fashion repair solutions, but is highly constrained by language-specific (morpho)syntactic rules. Moreover, the complementary distribution of the use of lexical initiators and retracting suggests a possible association between repair initiation and framing. The findings provide further evidence of how self-repairs which constitute a universal feature of interaction are shaped by local semiotic resources of Farsi, especially grammatical possibilities, lending further support to the interdependency of selfrepairs and syntax-for-conversation.

Key Words: self-repairs; Farsi conversation; repair initiation; repair framing

\section{Introduction}

Spontaneous speech in everyday interaction is characterized by routine occurrences of 'hitches' or 'disfluencies' of various sorts (Schegloff, 1979). They represent troubles which are handled either by speakers of troubles sources or by their co-participants. For the purpose of coordinating their actions through talk, interlocutors need to manage interactional contingencies (Sidnell, 2009), which could otherwise engender problems in intersubjective understanding (Hayashi, Raymond and Sidnell, 2013). Repairs refer to the treatment of troubles which recurrently figure in speaking, hearing and understanding talk-in-interaction (Schegloff et al., 1977). As sequential phenomena, they represent means developed in different languages to deal with troubles arising in talk-in-interaction (Karkkainen et al., 2007). It has been suggested that even if repairs are an invariable part of all languages and are systematically relevant to conversational turns, at least in certain sequential environments (Schegloff, 1979), they are organized differently in different languages (Fox et al., 2010). Constituting a part of the organization of repairs (Schegloff et al., 1977), self-initiated same-turn self-repairs (henceforth, self-repairs) refer to the process whereby speakers manage interactional contingencies which arise in the production of their utterances (Schegloff et al., 1977). A key feature of the repair engendered by self-initiation is that it is not generally embedded into the ongoing talk; rather, the speaker of the trouble source is observed to be putting the current interaction on hold ${ }^{1}$ and isolating the repair, "making of it an interactional business in its own right; i.e. exposing it" (Jefferson, 1987: 97).

Presenting results from a conversation analytic perspective aimed at yielding cross-linguistic evidence, the present study seeks to explicate how Farsi speakers initiate and frame self-repairs.

\footnotetext{
${ }^{1}$ I am grateful to an anonymous reviewer for drawing my attention to this point.
} 
The analysis presented attempts to look beyond sequential organization and includes frequency data to unravel the sequential and organizational properties of self-repairs. Repair initiation and framing have traditionally been related to three, though not necessarily distinct, components (Schegloff, 2013) involved in the trajectory of self-repair from repair initiation to its solution or completion: what needs to be repaired or 'trouble source', repair initiation, which is not necessarily explicit (Lerner and Kitzinger, 2015) and repair accomplishment (Schegloff et al., 1977). The present study seeks to trace the trajectory of self-repairs in terms of repair initiation and framing, which has been the object of a small body of research (Birkner et al., 2012; Fox et

al., 2010; Hayashi, 1994; Pfeiffer, 2014, 2017; Németh, 2012; Schegloff, 2013). Specifically, an attempt is made to determine how speakers indicate and manage interactional troubles as they arise in ongoing turns. By examining a language, not explored already, it is possible to see how locally available resources are mobilized to deal with potential interactional contingencies (Schegloff, 2006).

\section{Review of Literature}

Schegloff et al.'s (1977) seminal paper transformed repair from a domain of inquiry being treated epiphenomenal into a domain of conduct worthy of scholarly investigation (Hayashi et al., 2013). Sketching the organization of repair in conversation, Schegloff et al.'s (1977) study provided systematics of repair-related phenomena. Mainly drawing on this study, subsequent (intralingual) studies (Blackmer and Mitton, 1991; Egbert, 1996, 2002, 2004; Levelt, 1983; Levinson, 1983; Schegloff, 1979, 1984; Sidnell, 2007; Sparks, 1994; Zahn, 1984) established the highly organized nature of self-repairs in terms of phonetic and morpho-syntactic patterning (Fox et al., 2010) and showed that speakers rely on linguistic resources of their languages to effect self-repairs (Fox et al., 2017). These early studies were generally dominated by English (Karkkainen et al., 2007). However, in later studies, the analytic attention shifted to languages other than English and cross-linguistic comparative studies began to emerge (e.g., Fincke, 1999; Fox et al., 1996; Fox et al., 2009; Fox et al., 2010; Hayahsi, 1994; Laakso and Sorjonen, 2010; Karkkainen et al., 2007; Németh, 2012; Uhmann, 2001; Wouk, 2005). The findings of these studies into genetically related or unrelated languages have revealed that the workings of selfrepair are subject to considerable cross-linguistic variation (Fox et al., 2013), which, among other things, has been attributed to the linguistic resources which different languages make available to their users (Fox et al., 2017).

Interlingual conversation analytic studies have targeted various aspects of self-repairs. The vast majority of these studies have been concerned with the syntactic organization of self-repairs (e.g., Fincke, 1999; Fox and Jasperson, 1995; Fox et al., 1996; Karkkainen et al., 2007; Mirzayan, 2008; Rieger, 2003; Uhmann, 2001; Wouk, 2005). Some other studies have scrutinized retracting and/or replacement involved in self-repairs (Birkner et al., 2012; Fox et al., 2010; Hayashi, 1994; Pfeiffer, 2014, 2017; Németh, 2012) and within-word morphological selfrepairs (Fox et al. 2017). However, very few have targeted the lexical or non-lexical devices used to initiate self-repairs (Laakso and Sorjonen, 2010; Levelt, 1983; Sparks, 1994). Inspired by this comparative line of inquiry which has yielded contrastive findings (Birkner et al., 2012), the present study examines self-repairs which are initiated by the speakers of trouble sources themselves in the earliest "repair opportunity space" (Schegloff et al., 1977: 375). They are placed either within the same turn as the trouble source or directly adjacent to the trouble 
source (Hayashi et al., 2013) in the turn's transition relevance space, providing opportunities for managing troubles in talk-in-interaction (Fox et al., 2013).

\section{Data and Method}

The dataset, analyzed from a conversation analytic perspective, comprised 50 audio-recorded mobile phone calls, 50 video-recorded everyday conversations and $20 \mathrm{TV}$ interviews on a range of issues, representing both ordinary and institutional contexts. Given that some TV interviews were long and contained numerous instances of self-repairs, a certain number of self-repairs were chosen from each interview to ensure the representativeness of different kinds of interactions in the data. Simple repetitions, word searchers and self-repairs occurring in a place other than the current turn and in the transition-relevant place were excluded. The conversational data were examined to find examples of self-repairs. The inspection of the interactions yielded 636 instances of self-repair. They were then independently coded by the researcher and a research assistant in terms of repair operations worked out by Schegloff (2013). Disagreements over coding were at times resolved through negotiation. However, there were disagreements which could not be resolved. In addition, there were instances of self-repair which could not satisfactorily be classified or did not fit the categories above. For example, a speaker uttered a single sound without any clue or trace as to what he or she was going to say. Or there were some cases of the rearrangement of the elements in the turn-under-construction. These instances were coded as 'rest-category'. Apart from this class of self-repairs, thee major categories of replacings, insertings and abortings emerged from the data. Following Schegloff (2013), replacing refers to the substitution of a completely or partially uttered element with another usually of the same category whereas inserting is meant to refer to the addition or insertion of one or more elements in (part of) the turn-so-far. Aborting is defined as momentary or complete abandonment of what has been said or replacing the terms in which the turn-so-far has been couched. In addition, instances of self-repairs were also coded in terms of prosodic initiation, use or non-use of lexical initiators and turn-constructional framing used for repair contextualization (if any). Framing refers to the formulation of repair solution, which may involve the repetition of the element(s) before and/or after what is repaired. In the former case, referred to as 'retracting', the speaker "returns to an earlier point within an unfolding grammatical structure" (Birkner et al. 2012: 1413). It should be noted that retracting itself is not repair practice; rather, it is used to frame or contextualize self-repairs (Lerner and Kitzinger, 2015). In the interactional practice created by retracting, different types of self-repairs can ensue. Retracting is thus to be distinguished from recycling and repeating, which are treated as repairs.

\section{Results and Discussion}

\subsection{Repair Initiation}

Self-repairs typically take place in two phases: initiation and performance (Fox et al., 2013). As a part of its objectives, this study was concerned with exploring the ways in which self-repairs of different kinds are initiated in Farsi conversation. Table 1 provides information about the distribution of self-repairs in terms of their initiation.

Table 1

Distribution of self-repairs by repair initiation 


\begin{tabular}{lccc}
\hline $\begin{array}{l}\text { Self-Repair } \\
\text { Operation }\end{array}$ & Cut-off & \multicolumn{2}{c}{ Lexical Initiators } \\
\hline Replacings & 177 & yani & Other Lexical Initiators \\
\hline Abortings & 270 & 18 & 19 \\
\hline Insertings & 116 & - & 8 \\
\hline Rest-Category & 17 & - & - \\
\hline Total & $\mathbf{5 8 0}$ & $\mathbf{3 1}$ & $\mathbf{2 7}$ \\
\hline
\end{tabular}

Different kinds of troubles can trigger prosodic cut-off and other speech perturbations, which, by virtue of their function as potential repair initiators, bring about "possible disjunction with the immediately preceding talk" (Schegloff, 2007: 207). This table provides empirical evidence of the use of prosodic cut-off as a technique to initiate self-repairs in Farsi across different repair operations. The patterns emerging in self-repair initiation are discussed and exemplified in the following sections.

\subsubsection{Prosodic Initiation of Self-repairs}

As evidenced in such languages as Finnish (Laakso and Sorjonen, 2010), Dutch (Berg, 1986; Level, 1983), English (Fox et al., 1996; Jasperson, 1998, 2002; Local, 1992), French (Bredart, 1991) and Japanese (Hayashi, 1994), cut-off, as the 'basic format' for same-turn self-repair (Schegloff et al. 1977) breaks off the flow of speech within a word or upon its completion and represents the most frequent way of initiating self-repairs. Self-repairs are initiated with a range of other non-lexical speech perturbations (Schegloff et al., 1977) which are underrepresented in the data set. Given that cut-off initiates repair on elements of turns produced already and is thus 'postpositioned', it is syntactically disjunctive in that it interrupts the syntactically projected turn-so-far (Schegloff, 1979), disrupts the pace of ongoing talk and suspends the talk which may be later resumed after repair proper (Lerner and Kitzinger, 2015). The mere presence of this perturbation, which could index the possibility of the immediately following repair initiation (Schegloff et al., 1977), is not sufficient to indicate that a repair is imminent (Lerner and Kitzinger, 2015). In terms of its function, as a non-specifying speech disfluency, it does not herald a specific repair operation (Laakso and Sorjonen, 2010). In the corpus of the present study, it indexes any repair operation such as replacing, aborting or inserting, as instantiated in the exemplars below.

In this exemplar which features an inserting self-repair, a teacher has made a call to a course coordinator to discuss the schedule drawn up before the commencement of a new term.



\footnotetext{
${ }^{2}$ For the purpose of the transcription, the Jeffersonian Transcription System is used (Atkinson and Heritage, 1999). Four lines of transcript appear in data excerpts: Farsi original, using Farsi alphabet, the transliteration in English alphabet, a gloss, and an idiomatic English translation. The Leipzig Glossing Rules have been adopted for person morphological inflections: "1SG" = first person singular, "2SG" = second person singular, "3SG" = third person singular, "1PL" = first person plural, " $2 \mathrm{PL}$ " = second person plural, and "3PL" = third person plural (Comrie, Haspelmath and Bickel, 2015).
} 


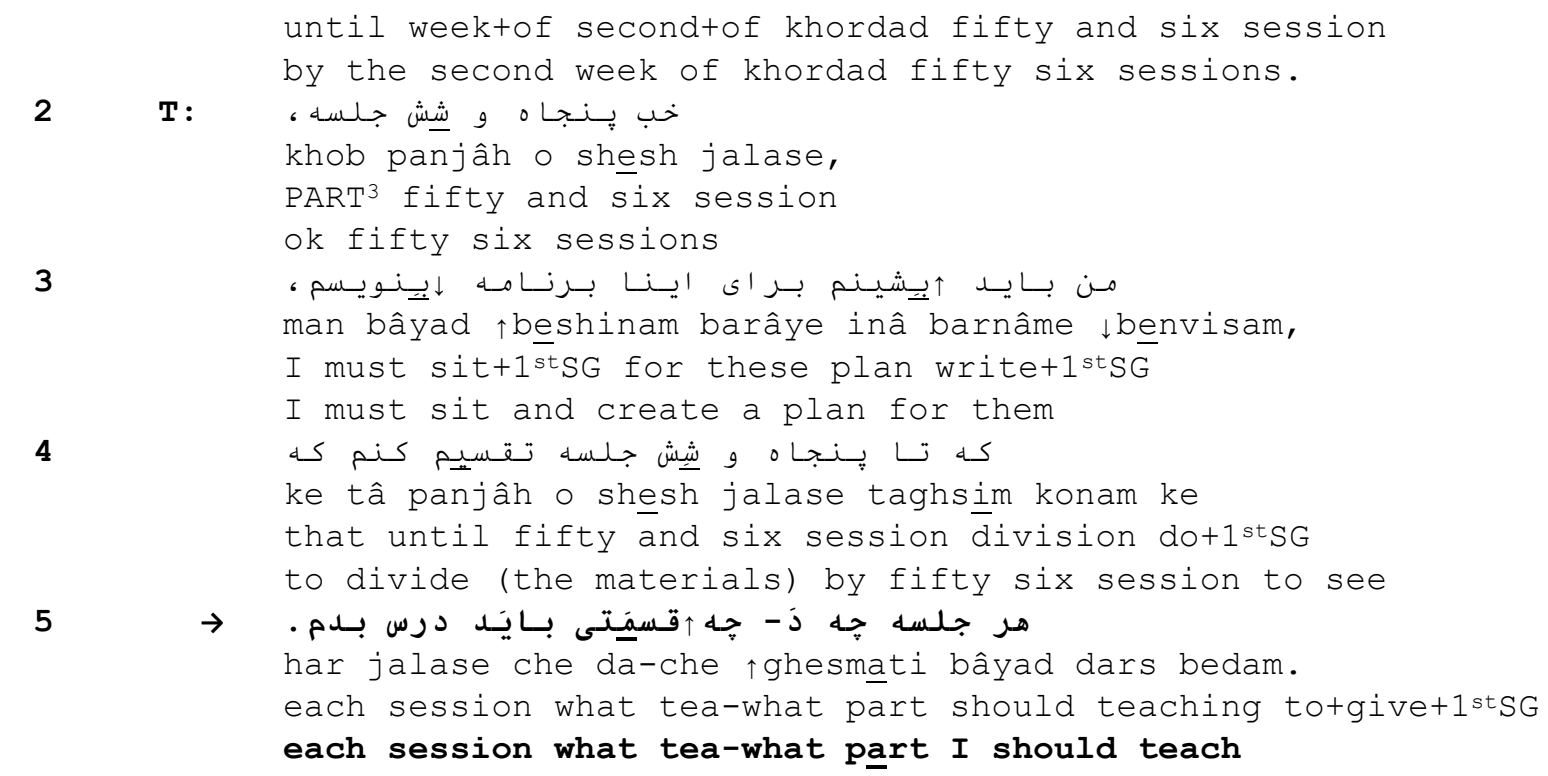

In the prior talk (not described here for space reasons), the course coordinator asked the teacher to begin her language classes on the first day of the following week. After obtaining required information about the number of sessions during the whole term, the teacher is explaining why she cannot begin her classes without adequate preparation and lesson planning. In line 5, she prematurely terminates what is projected to be dars (teaching) with a 'glottalized cut-off' (Fox and Jasperson, 1995), which has been shown to have 'turn-holding' functions (Ogden, 2001) and inserts che ghesmati (which part) before it in the emerging turn. The insertion is not necessarily about addressing a problem in the turn-in-progress (Schegloff, 2013). The cut-off involves a glottal stop in this case, which is due to the environment in which it takes place (Jasperson, 2002). In addition, the inserted word is clearly emphasized, contributing to the prosodic prominence of the self-repair. As indicated by the upward point arrow in line 5, there is a rise in pitch, and a prominent peak occurs on the second syllable of the inserted word 'ghesmati' (a part). The replacement is uttered on a pitch noticeably different from the interrupted word, leading to relatively higher amplitude and duration of the repair item. The self-repair is utilized to insert a phrase that adds specificity to the teaching and shows the teacher's orientation to turn construction to perform the 'interactional work' which the turn has been designed to perform (Drew et al., 2013).

Prosodic break-off may also be used to preface replacing self-repairs . Such a case is illustrated below.

Exc. 2 (\#172, TV INT \#9,4:05, IR=interviewer, IE=interviewee)

1

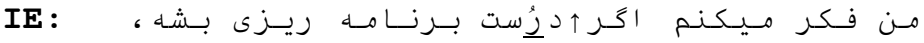

man fekr mikonam agar $\uparrow$ dorost barnâmerizi beshe,

I think+1stSG if proper planning become

I think if proper planning is in place

2

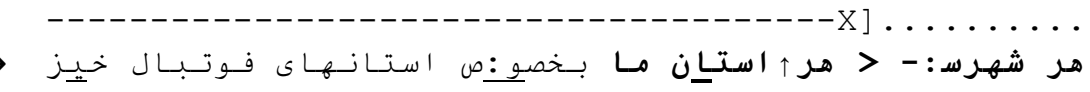

${ }^{3}$ Particle 


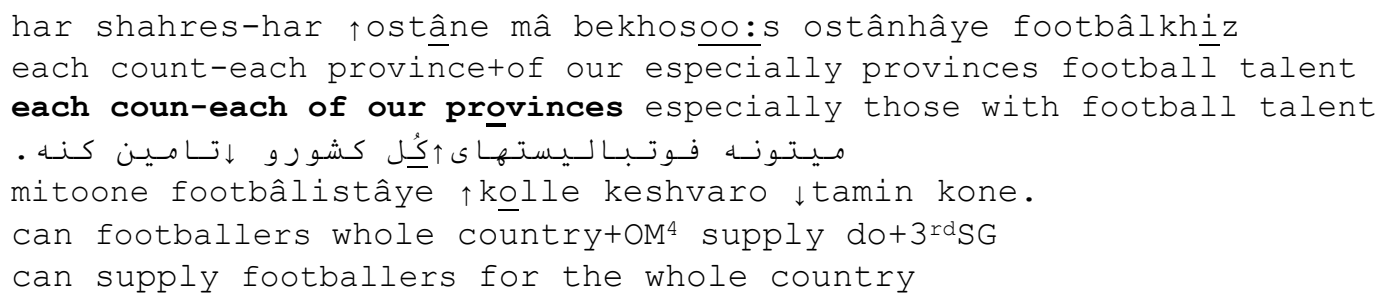

Here the speaker initiates the repair with a cut-off in line 2 and aborts what he was in the course of saying, thereby signaling a trouble with the ongoing production of the turn-underconstruction. Given the relatively sonorant environment in which the closure takes place, the sound segment [s] is lengthened, producing what Nakatani and Hirschberg (1993) term 'interruption glottalization'. Given the context in which cut-off takes place, there is no complete closure, as indicated by the lengthening at the cut-off point. Subsequently, the speaker replaces what is on the way to shahrestân (county) with the word ostân (province or state) and then proceeds to complete the sentence. It is notable that, as indicated by the $>$ sign, the resumption of speech after the cut-off is quite fast. An additional resource which serves as a prosodic cue for the recipient and has a specifiable sequential location is the prosodic emphasis (i.e., stress) on the second syllable of the word ostân (province). Moreover, as indicated in the transcription, prior to the replacing repair, the guest was not gazing at the host. However, upon the initiation of the repair, he shifted his gaze to him. The shift in gaze, which is a practice deployed to achieve mutual orientation (Egbert, 1996), seems to be employed to attract the attention of the host to the repair. Another observation to be made is that the trouble source and the replacement belong to the same grammatical category and are semantically related. As projected by the determine har (each) recycled in the self-repair, the repaired segment is the 'sort of thing' the candidate repair is, which furnishes another interactionally relevant resource for the recipient to locate what is being repaired (Schegloff, 2013). Therefore, the self-repair does not have any syntactic effect. However, it possibly leaves an interactional effect in that not all traces of the word starting to be said are excised by the replacement (Schegloff, 1979). The replacing is occasioned by the fact that in Iran, football teams are typically recognized with reference to states or provinces rather than individual counties or cities.

In terms of prosodic marking, apart from a glottal stop, which indicates that a repair is going to be initiated, self-repairs are overwhelmingly marked in the current dataset even when they are followed by lexical initiators and are typically high-pitched. Even if this strategy may have some disruptive effect on the flow of speech (Cutler, 1983), it makes the repair noticeably different from the original troublesome item. As a result, the repair item becomes particularly salient, which is due to its pitch or loudness, or a combination of the two. The markedness provides a resource which recipients can exploit to contextualize the repairs performed (Levelt and Cutler, 1983). Therefore, there is some prosodic patterning which applies to prosodic repair markers. This patterning, which runs counter to normal prosodic marking in Farsi (Sadat-Tehrani, 2009), can be seen both in the foregrounding performed by glottal stops and the prosodic marking of repairs proper.

\footnotetext{
${ }^{4}$ Object Marker
} 
The examples above illustrated the occasions on which cut-off is followed by inserting and replacing operations. Still, another possibility is that the cut-off is followed by an aborting selfrepair. In Excerpt 3, a man (A) and a woman (B), who are co-hosting a radio program, are talking about a trial which is about to begin in a law court.

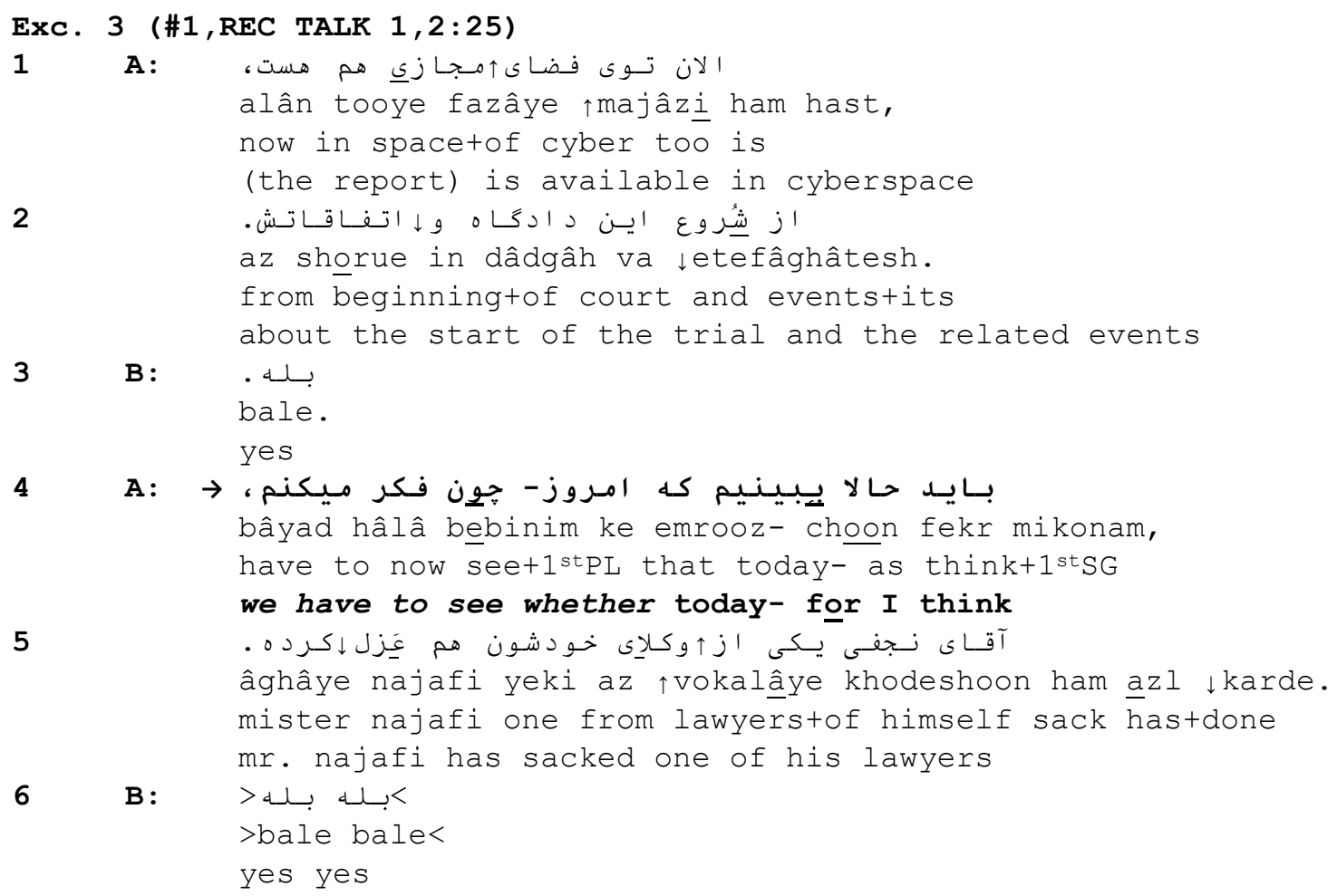

In line 4, the man completely aborts the emerging sequence, leaving the continuation unexpressed and launches a new sequence. The repair proper after the cut-off is different from an element which is due next (Schegloff, 2013). The abandonment involves forsaking both the action and the formulation to fashion it. Given that the turn-under-construction is aborted early on, it is not clear how it would have proceeded. However, it seems that, based on the foreshadowing and the format exhibited in line 4, it has something to do with speculation about the outcome of the trial. The aborting seems to have been conditioned by what the man recalls about the same trial, which, for him, takes precedence over what he was about to say.

The upshot of the observations made above is that prosodic cut-off, which may signal any repair operation (Schegloff et al., 1977), halts the progressivity of speech and may signal any repair operation. While these observation corroborate earlier findings about the function of prosodic cut-off and other disfluencies and the preponderance of cut-offs in self-repair initiation, they show some prosodic patterning of self-repairs in Farsi talk-in-interaction. As illustrated below, prosodic cut-offs may be followed by a variety of lexical devices.

\subsubsection{Lexical Initiation of Self-repairs}

Even if prosodic break-offs are a pervasive presence in repair initiation in Farsi, they may at times be followed by lexical initiators such as yani and a range of other lexical means (given in 
the appendix). Lexical devices are used to index both replacing and aborting self-repairs but, as evidenced in other languages such as Finnish (Laakso and Sorjonen, 2010), they are not used to initiate insertings. Unlike prosodic cut-offs, they are routinely prepositioned and carry forward the 'syntactic projection' of the utterance-so-far (Schegloff, 1979), alerting the co-participant to the possibility that a repair is underway (Lerner and Kitzinger, 2015). Lexical initiators have already been related to specific repair operations. For example, negation words are used to signal an incipient replacing repair which corrects an error in Dutch (Levelt, 1983). In English, negation words and the initiator I mean could project a replacement repair (Sparks, 1994). Or and well are used to index a better alternative to the trouble source or the revision of an inadequate formulation (Lerner \& Kitzinger, 2015. 2019). In Finnish, eiku (a combination of a negation word and a conjunction) and tai (as a disjunctive conjunction) are used to project replacement repairs, while the former could signal abortings, too (Laakso and Sorjonen, 2010). Additionally, they have been associated with specific sequential positions and functions. In Farsi talk-in-interaction, the pattern which can be discerned from the scrutiny of the data is the deployment of yani as a lexical initiator to project something about the nature of the subsequent repair. In English, I mean is used to initiate a replacement self-repair (Sparks, 1994) or the abandonment of an emerging turn (Jasperson, 1998). In Farsi, yani is likewise used in a capacity to herald upcoming self-repairs. As observed in Table 1, yani-prefaced repair operations constitute about half of all cases of lexically-initiated replacings. Moreover, its use is more applicable to replacings than abortings. In the latter case, the action to be performed remains the same, but the yani-prefaced self-repair typically alters only the design of the action, involving morpho-syntactic changes (Drew et al., 2013). Out of the 13 cases of abortings which are followed by yani, 11 cases involve reconstructing or reorganizing the (emerging) action before the repair-oriented speech perturbation (Schegloff, 1979). Therefore, as a preface to the imminent self-repair, yani provides Farsi speakers with apparently unique possibilities for a social action. This at least partially language-specific character of a repair initiator has not been reported in the literature.

Originally derived from the Arabic root ' $n \bar{a}$ (to mean, to concern), yani in Modern Farsi is considered as an adverb and is defined as 'meaning', 'that is' and 'I mean' (Anvari, 1988; Sadri and Hakami, 2002). It represents a key lexical device to index an upcoming self-repair or to indicate that a repair has been carried through when the particle follows the candidate repair. The use of yani is restricted to replacings and certain aborting self-repairs. It is predominantly used immediately after the repairable and occasionally after the repair proper, as a post-indication of repair. This pattern is illustrated with concrete examples from the data.

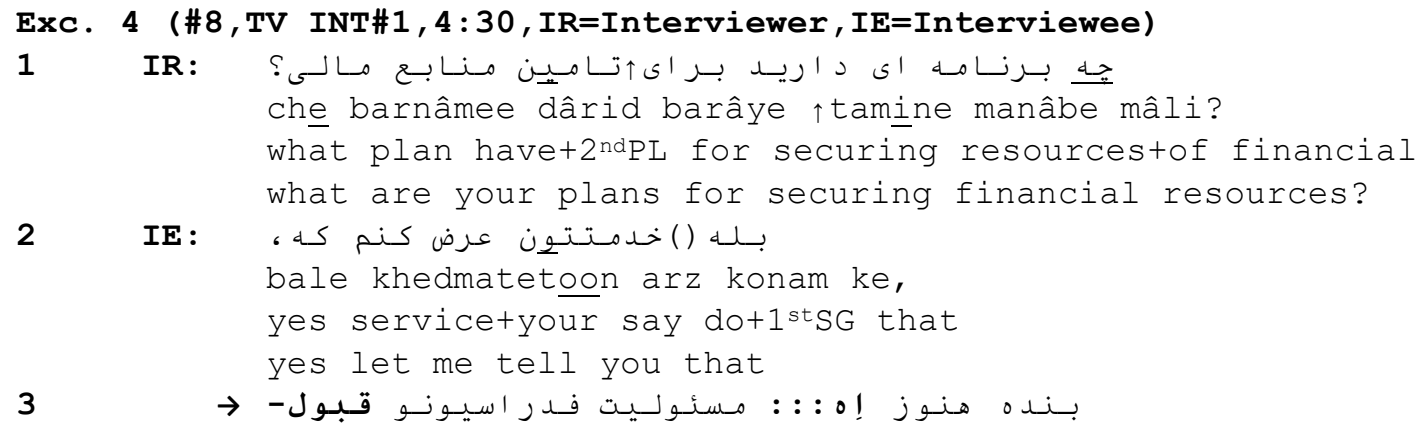




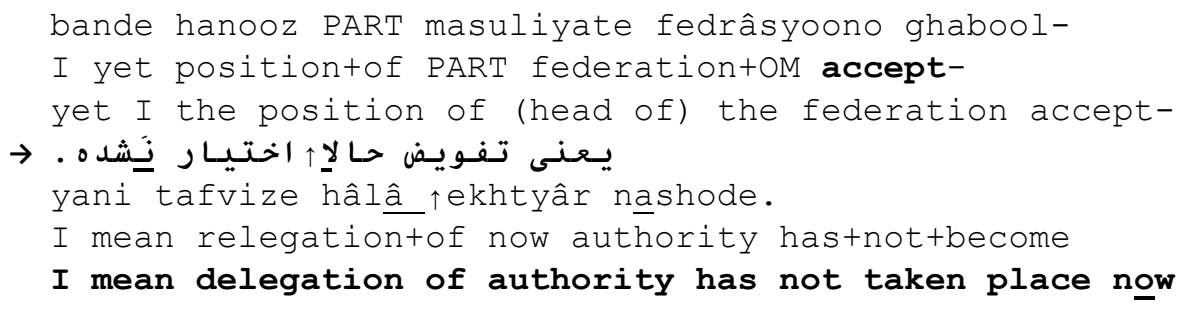

In this fragment of a TV program, the host is talking to the newly elected president of the Iranian Wrestling Federation over the phone. There has been huge controversy over who is eligible to nominate and even over the election itself. The host poses a question to the guest in line 1, which concerns his future plans. In line 3, the guest exhibits some hesitancy by using a particle, which, as evidenced in other languages (Lerner, 2013), might be indicative of a 'trouble ahead' in Farsi. On this same line, he uses the word ghabool (acceptance), which evidently does not fit the context and is being treated by the guest as troublesome in some way. After all, he has nominated for the presidency of the federation of his own free will and accepting or not accepting the position is out of question. Immediately hereafter, following the lexical initiator of yani, which projects a prospective repair, he interrupts the forward progress of his turn and replaces ghabool with a formulation which more closely describes one's assignment to the position in question. Even if the word before the cut-off and its replacement belong to the same syntactic and semantic category, given the consequentiality of the turn design (Drew et al., 2013), they contribute to turn construction in different ways. The first one describes the responsibility of the new position as a personal one whereas the replacement signifies formally relegating the responsibility to somebody.

This lexical device can also be used to initiate aborting repair operations, though less frequently. The excerpt below is an example of aborting in which use is made of the lexical device of yani.

ExC. 5 (\#193, TV INT\#9,18:33, IR=Interviewer, IE=Interviewee)

1

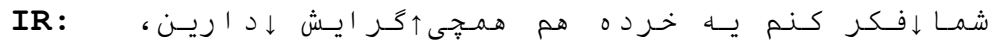

shomâ $\downarrow$ fekr konam ye khorde ham hamchi $\uparrow$ gerâyesh $\downarrow$ dârin, you think+1 ${ }^{\text {st }} \mathrm{SG}$ a little too somewhat tendency have+2 ${ }^{\text {nd }} \mathrm{SG}$

I think you too have a little tendency toward

2

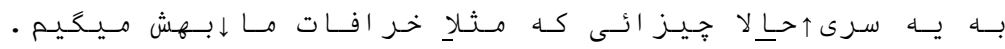
be ye seri $\uparrow$ hâalâ chizâyee ke masalan khorâfât mâ $\downarrow$ behesh migim. to a series anyway some things which example superstition to say+1 ${ }^{\text {st }} \mathrm{PL}$ to a series of things which we anyway call superstition for example

3

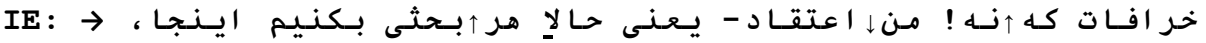
khorâfât ke $\uparrow$ na! man $\downarrow$ eteghâd- yani hâlâa har $\uparrow$ bahsi bekonim injâ, superstition that no I belie- I mean now each argument do+1 ${ }^{\text {st }} \mathrm{PL}$ here superstition not I belie- I mean whatever argument we make here now

In the excerpt above, the host is interviewing a football coach, who is rumored to believe in superstition. Given the sensitivity of the issue, the host exercises utmost care not to offend the coach, showing his concern for the sensitive matter he is raising by using a 'euphemistic 
formulation' (Lerner, 2013) and manages to put the question to the guest with 'quiet impropriety' (Schegloff, 2003). In line 3, in addressing the question posed, the interviewee first refutes the rumor and proceeds to elaborate on it. However, he breaks off what he is about to say by halting the stream of his speech, suspends the progress of the sequence in the making (Hayashi et al. 2013) and uses the lexical initiator of yani. This is followed by an account of the audiences' possible impression of or reaction toward the arguments to be made, which is noncontiguous with what went on before the cut-off.

As instantiated in such languages as English, some lexical initiators have been examined in terms of the sequential environment in which they are used and are thus called 'repair prefacing' (Lerner and Kitzinger, 2010, 2015). However, in Farsi on some occasions, lexical devices follow the candidate repair. Excerpt 6 exemplifies a self-repair deviating from the architype worked out for lexically initiated self-repairs. The excerpt is drawn from a roundtable in which a moderator and a number of panelists are discussing whether women should be given more freedom or less in wearing the hijab and what the possible repercussions are.

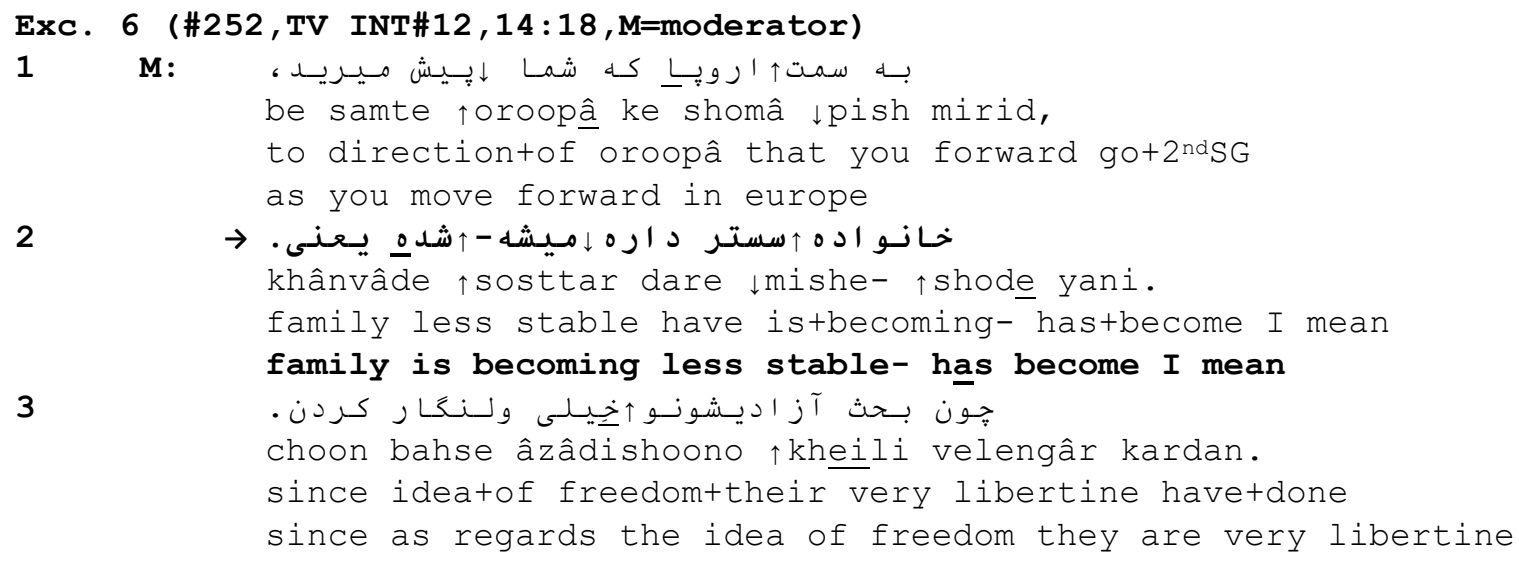

Here the roundtable moderator, who is a university professor, is making a comparison between different parts of the world in terms of the latitude given to women. He is trying to make an argument that more freedom leads to more social problems. In line 2, as he is supposedly depicting the situation, he first talks about the worsening situation in Europe. However, he briefly halts the forward progress of his speech and replaces mishe (is becoming) with shode (has become), followed by the lexical initiator of yani. In terms of turn design, the replacement shows the moderator's orientation to the action which he is trying to accomplish (Drew et al., 2013). The sections above dealt with the first phase of self-repair, which is repair initiation and sought to build a case for the relevance of lexical and non-lexical initiators to self-repairs. A phenomenon which is relevant to the performance phase of self-repair is retracting, which represents a preframe to repair accomplishment and might as well include a postframe which involves the repetition of the element(s) subsequent to the trouble source (Lerner and Kitzinger, 2015). Retracting is thus relevant to the phase of repair solution in the trajectory of repair and is not treated as a self-repair in its own right. The following section makes an argument of the framing of self-repairs.

\subsection{Repair Framing}


Apart from using prepositioned or postpositioned repair initiators as trouble alerts, speakers at times retract back beyond the trouble source and recycle the element(s) before the cut-off and even after it. Retracting could be motivated by processability concerns for recipients (Kazemi, 2006; Pfeiffer, 2017; Schegloff, 2013). Alternatively, it could be occasioned by motivations to maintain a syntactic bond between the elements involved in the repair (Birkner et al. 2012; Fincke, 1999; Fox et al., 1996; Rieger, 2003; Schegloff, 1979, 1987; Uhmann, 2001). Retracting is interactively relevant to the turn construction (Schegloff, 1987, 1979, 2013) and is designed to enable the recipient to identify the repairable (Pfeiffer, 2017). Given the relevance of 'syntaxfor-conversation' to self-repairs (Schegloff, 1979), and given that they are even 'interdependent and co-organizing' (Fox et al., 1996), as epitomized by retracting (see Fox and Jasperson, 1995; Laakso and Sorjonen, 2010; Németh, 2012; Uhmann, 2001), an attempt was made to provide a description of 'turn-constructional' framing of self-repairs (Lerner and Kitzinger, 2015) in Farsi talk-in-interaction. This gives insight into how speakers deploy language-internal syntactic resources to frame self-repairs. For this purpose, individual instances of self-repair were investigated to determine whether there is any retracting involved in effecting self-repairs. It is noteworthy that the examination of the data revealed that retracting is infrequent in aborting selfrepairs, as evidenced in the following exemplar.

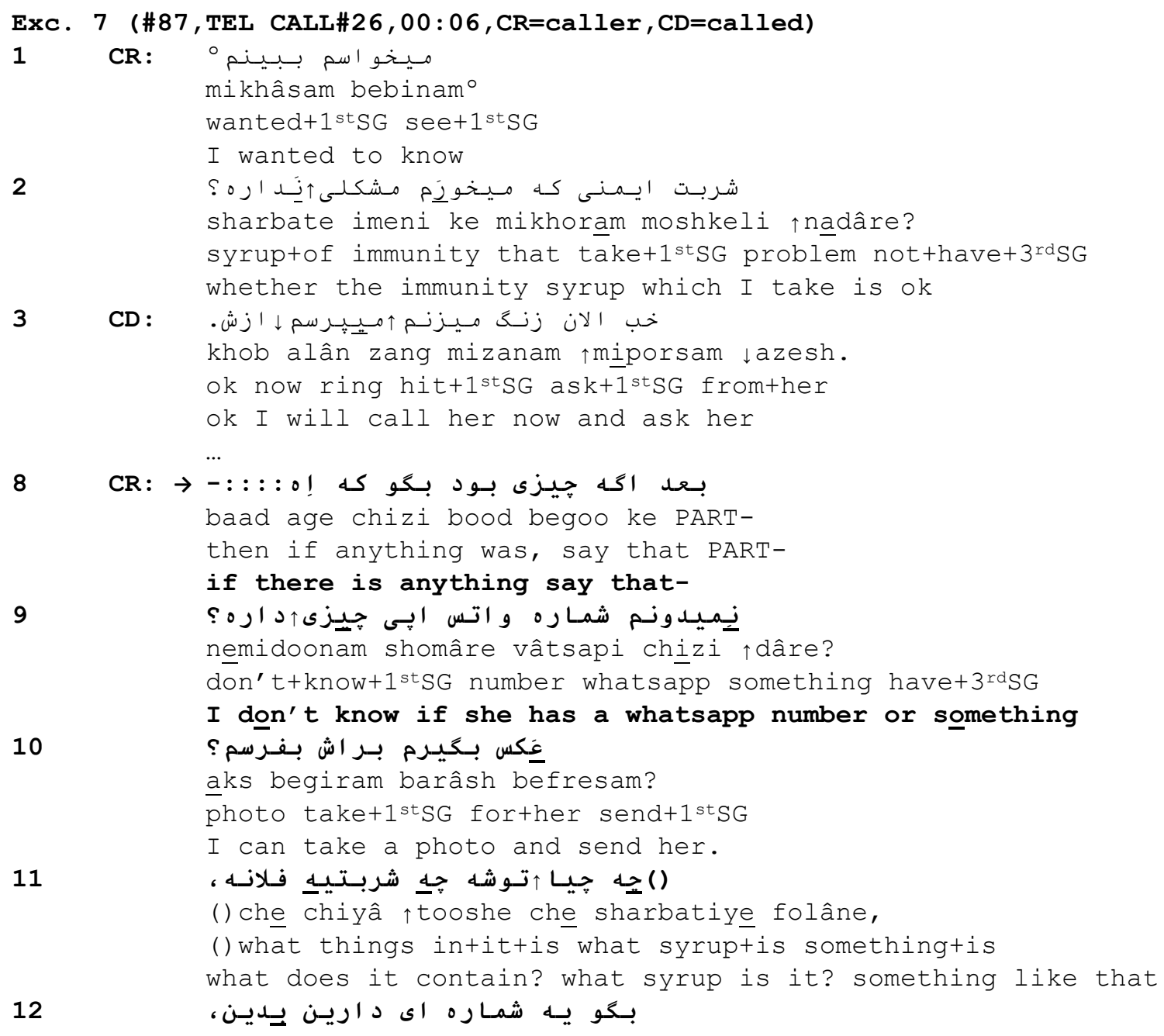


Begoo ye shomâre ay dârin bedin,

say a number if have+you give+you

say, if you have a number, give it

مـن عَكس بـحـيـرم بـر اتـون بـفـرسم .

man aks begiram barâtoon befresam.=

I photo take+1stSG fortyou send+1stSG

I can take a photo and send you.

14

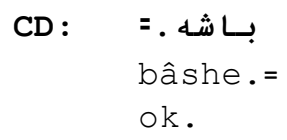

In this excerpt, a man has called his wife to seek the advice of her colleague on a medicine he is taking. In line 2, he first tells his wife which inquiry to make on his behalf. As his wife has already left her office, she indicates that she will call her colleague to make inquiries.

Subsequently, they engage in terminating the call (not included here). However, as revealed later in the incipient talk, and especially the particle used which seems to be revelatory of his hesitancy and is forward-oriented (Schegloff, 1979), the man is about to provide some information about the medicine, but changes his mind and decides to reach the colleague himself and send the information by WhatsApp or some other means. Thus, he aborts providing information about the medicine, which based on what is foreshadowed in lines 8 and 11, is the next item due, and proceeds to make inquiries about whether his wife's colleague has a WhatsApp number or something. It could be seen that the resumption of the talk after the perturbation marked by the particle in line 8 has nothing to do with what he was in the course of saying. Therefore, there is no ground for retracting, and the construction of a new turn helps the recipient to locate the self-repair.

Even if the exemplar above and the vast majority of abortings in the data set did not involve retracting, this does not mean that there was no recycling of the part(s) of the repairable in the accomplishment of abortings; rather, for example, in changing the design of an action, which represents a sub-category of abortings and a speaker changes the terms in which the trouble source is phrased (Schegloff, 2013), the repairing action may include one or more elements from the part preceding the cut-off. Apart from such cases, occasioned by the potential consequentiality of this repair operation, the identity and composition of the turn-so-far are not retained in the repair proper (Schegloff, 1979), and the turn after the resumption of the talk may diverge from the first in many respects (Schegloff, 2013). In the same vein, Laakso and Sorjonen (2010) found that in 'abandonments', the second formulation usually diverges substantially from the first in multiple ways and that unlike replacements and insertions, abandonment self-repairs do not preserve the syntactic formulation of the turn which is interrupted. Therefore, retraction which serves a resource for the listener to integrate the repair into the turn-so-far (Pfeiffer, 2017) is not frequent in abortings. On these occasions, speakers abort a turn in the making and begin a turn anew, without any effort to try the same turn constructional unit again or in a different manner (Schegloff, 2013). The results of retracting applicable to different repair operations appear in Table 2.

Table 2 
Frequency of self-repairs in terms of retracting

\begin{tabular}{lccc}
\hline $\begin{array}{l}\text { Self-repair } \\
\text { Operation }\end{array}$ & $\begin{array}{c}\text { Frequency of Self- } \\
\text { repairs }\end{array}$ & $\begin{array}{c}\text { Retracting with } \\
\text { Lexical Initiation }\end{array}$ & $\begin{array}{c}\text { Retracting without } \\
\text { Lexical Initiation }\end{array}$ \\
\hline Replacings & 201 & $6(3 \%)$ & $62(30 \%)$ \\
\hline Insertings & 139 & - & $48(34 \%)$ \\
\hline Abortings & 277 & 1 & $10(3.6 \%)$ \\
\hline Rest-Category & 19 & 2 & - \\
\hline Total & $\mathbf{6 3 6}$ & $\mathbf{9}$ & $\mathbf{1 2 0}$ \\
\hline
\end{tabular}

An observation to be registered from the table above is that in about $80 \%$ of all the cases launched in the corpus, self-repairs start up directly at the repairable segment, which involves 'minimal span of retraction' (Pfeiffer, 2017). This suggests Farsi speakers' concern for rapidity of carrying out self-repairs, as the most important motivation shaping self-repairs, and their preference for the interactional principle of progressivity (Pfeiffer, 2017; Schegloff, 2007, 2013). On the other hand, Farsi speakers sometimes go back beyond repair segments and include one or more elements before the repairable. In the table above, retracting makes up a good number of the operations of repair solution (about 34\% in both replacings and insertings), which, at least in part, arises from the fact that the mere occurrence of self-repairs is consequential for the shape of conversational turns and the arrangement of their elements (Schegloff, 1979). In carrying out replacings and insertings, self-repairs are performed within the 'retained identify' of turn-underconstruction (Schegloff, 1979), and speakers may retract to and repeat the word(s) preceding the trouble source. The scope of retracting provides an evidential basis suggesting that speakers reactivate the syntactic formulation prior to the repair (Birkner et al., 2012). The following table provides information about how far speakers go back within the original syntactic structure. Given that retracting rarely happens in abortings, only replacings and insertings are examined in terms of retracting.

Table 3

Points of Retraction in Replacings and Insertings

\begin{tabular}{lccccc}
\hline \multirow{2}{*}{$\begin{array}{l}\text { Self-repair } \\
\text { Operation }\end{array}$} & NP & PP & VP & Sen./Cla. & Other \\
\cline { 2 - 6 } Replacings & 23 & 28 & 4 & 9 & 4 \\
\hline Insertings & 18 & 7 & 1 & 2 & - \\
\hline Total & $\mathbf{4 1}$ & $\mathbf{3 5}$ & $\mathbf{5}$ & $\mathbf{1 1}$ & $\mathbf{4}$ \\
\hline
\end{tabular}

The table suggests that the 'point of retraction' (Pfeifer, 2017) (i.e. the position the speaker goes to when performing self-repair) is predominantly the beginning of noun phrases and prepositional phrases and that other points are not frequently opted by Farsi speakers. Specifically, the data indicates that 'constituent-internal' retracting is typical of Farsi data (Fox et al. 1996). It is notable that except for verb phrases, Farsi is a head-first language (Dabir Moghaddam, 2013). In terms of retracting, the organization of self-repairs is both contextsensitive and context-free. On some occasions, retracting works in Farsi like many other 
languages. As in some other languages such as English, (Fox et al., 2010), German and Swedish (Birkner et al. 2012; Uhmann, 2001), Farsi exhibits a strong preference for the preposition as a point of retraction. This holds true for noun phrases as well. On the other hand, the organization of self-repairs is also context-sensitive in that there are features of Farsi that allow for unique ways to formulate self-repairs. For example, retracting to the beginning of grammatical structures other than noun phrases and prepositional phrases is underrepresented in the data. Therefore, some self-repairs are constrained by Farsi-specific syntax. Unlike English (Fox and Jasperson, 1995; Fox et al., 1996), Farsi speakers do not frequently recycle back to the beginning of verb phrases, sentences and clauses, which is another indication of how Farsi syntactic practices constrain the organization of self-repair.

By framing the repaired segment, retracting provides a resource for locating what is being repaired (Pfeiffer, 2017; Schegloff, 2013). The preponderance of retracting in the corpus, compared with lexical initiation, suggests Farsi speakers' orientation to syntactic resources to frame self-repairs. Excerpts 8 and 9 exemplify the use of retracting either with or without lexical initiation.

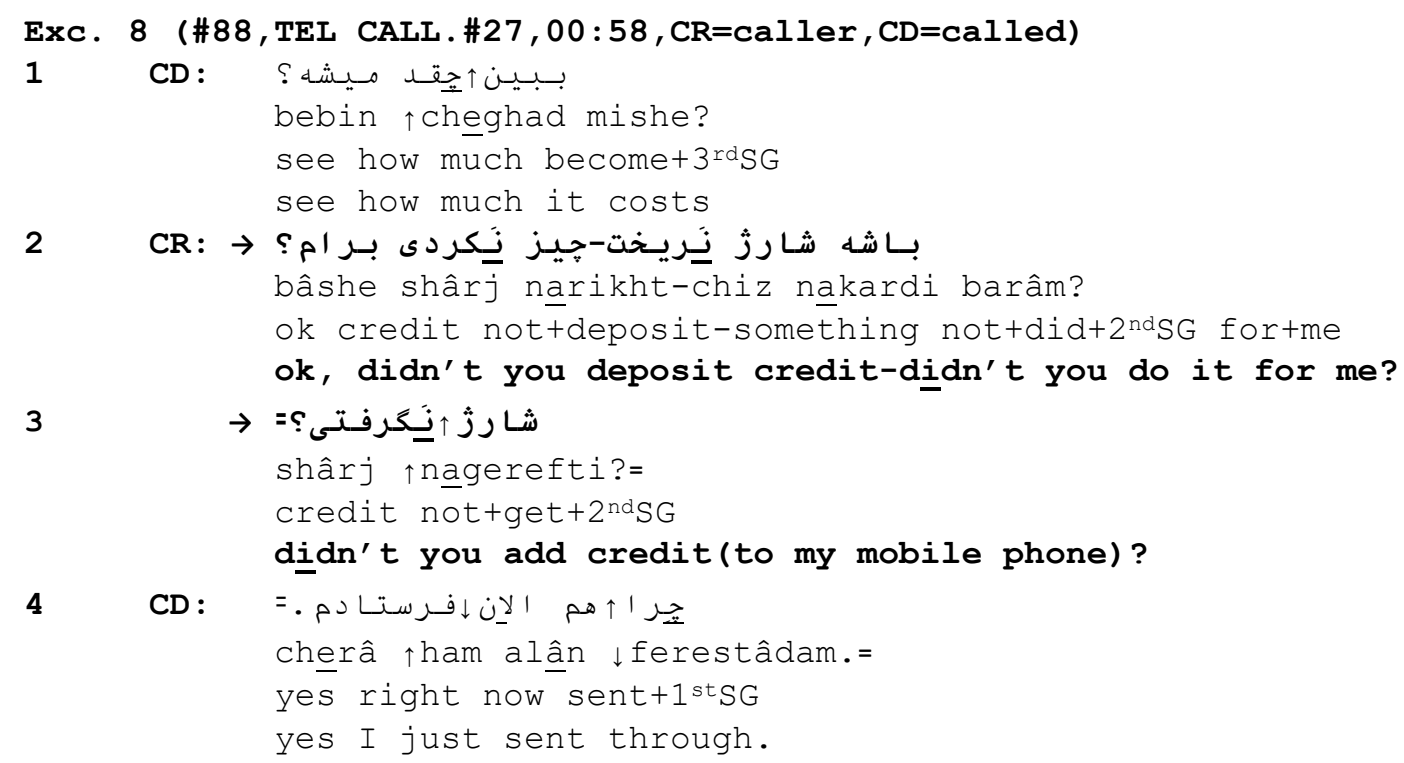

In this excerpt, a woman has called her husband to see whether she should go to a laboratory nearby to take some tests. Her husband first asks her to make inquiries about the cost (line 1). His wife agrees to do so and goes on to make an inquiry about whether her husband has added credit to her mobile phone. She mistakenly uses the word narikhti (not depositing), which is a related word, and immediately cuts off the trouble source to replace it with the right word, which as shown by the part immediately after the cut-off, she does not quite recall. This part seems to function like a 'prospective indexical' (Goodwin, 1996) or a 'dummy term' (Schegloff, 1982) in Farsi functioning as a placeholder filler or 'delay token' (Hayashi et al., 2013) occupying the position at which the next element is due (Schegloff, 1979). It both allows the speaker to search for the right word and to signal to the co-participant that a repair is underway. Subsequently, by launching a second effort, she finds the right word (gereftan meaning 'to get' or 'to add'). In the replacement, she retracts to the original formulation before the cut off, which is a 'sequence- 
structurally' important utterance-initial locus in conversation (Schegloff, 1987) and then replaces the verb narikhti (not depositing) with nagerefti (not getting, not adding).

In the example above, retracting followed a self-repair which was lexically initiated. This was not a frequent occurrence in the data. On most occasions, as evidenced in the following exemplar, retracting is launched in the absence of lexical initiation (Table 2):

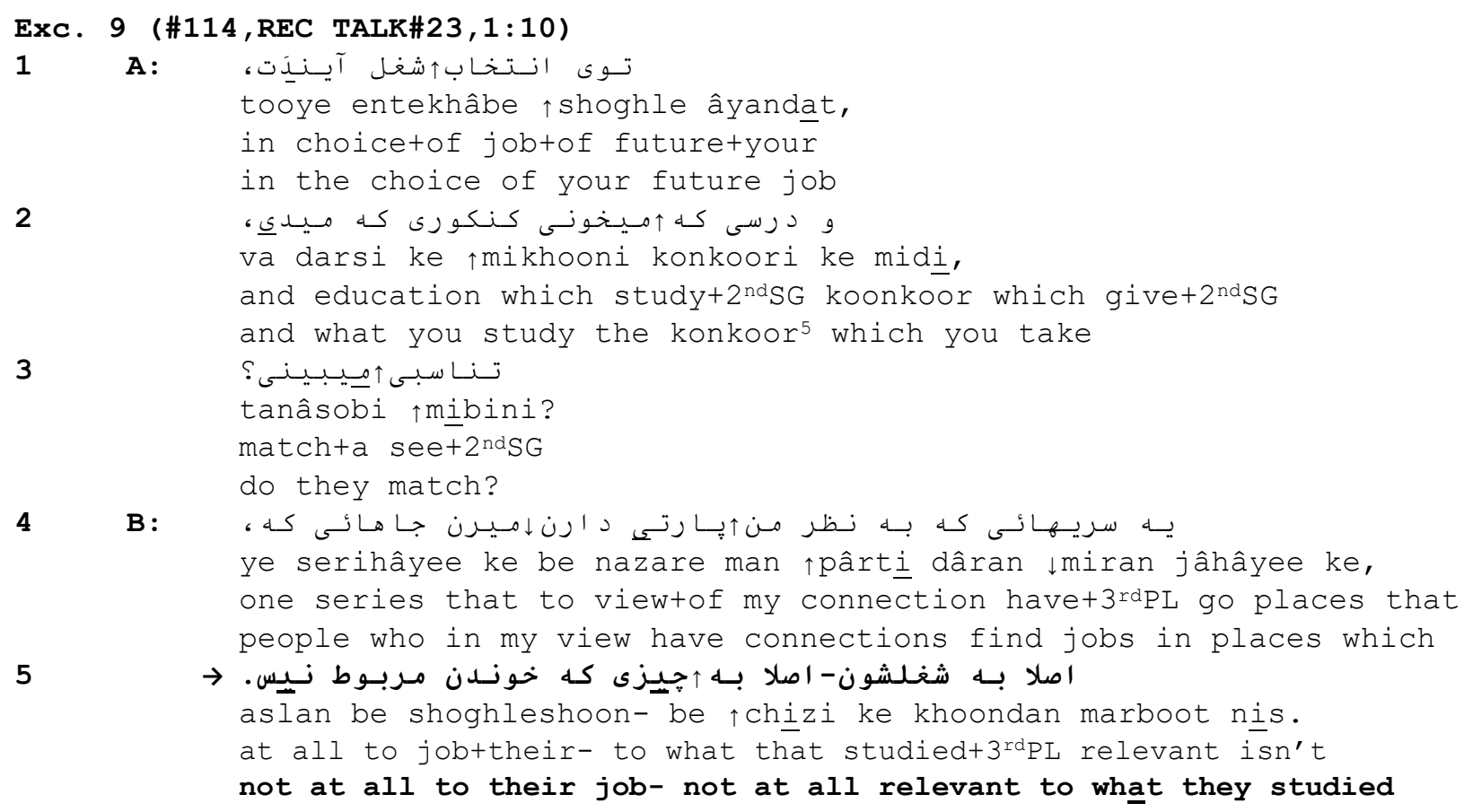

The talk is about whether pursuing higher education means better employment prospects. In line 5 , the speaker is partway through a turn when a repair is initiated non-lexically, which preframes 'aslan be' from the part before the cut-off. This is followed by a candidate repair in which 'shoghleshoon' (their job) is repaired to 'chizi ke khoondan' (what they have studied), maintaining the original formulation before the cut-off. The speaker recycles back to the beginning of the prepositional phrase, which is a major locus of retracting (Schegloff, 1987, 2013). An observation to be made about the self-repair launched above is that there is no perturbation in the progressive realization of the talk. However, the 'turn-constructional framing' (i.e., repeating the element(s) before and/or after the trouble source) offers a resource for the speaker to provide information about the nature of the trouble in the original formulation and how it is managed (Lerner and Kitzinger, 2015). Retracting is also applicable to insertings which are not lexically initiated. In the following excerpt taken from a TV interview, the interviewee, who is an economist, is commenting on the problems which the Iranian car industry faces and what the contributing factors are.

ExC. 10 (\#127,TV INT\#7, 7:00, IR=Interviewer, IE=Interviewee)

1

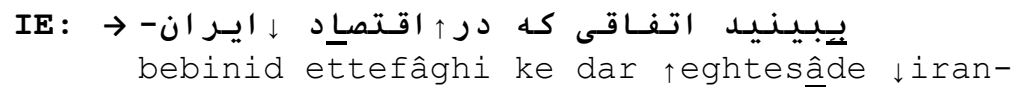

${ }^{5}$ It refers to the countrywide university entrance examination in Iran. 


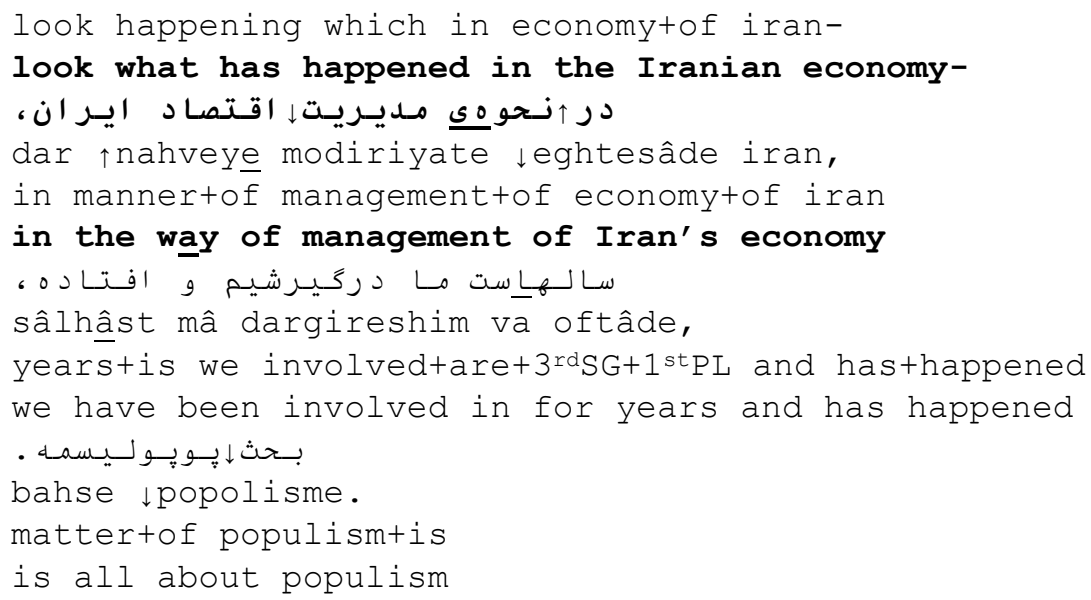

In line 1, the interviewee interrupts the turn in the making and inserts a noun phrase in the middle of what he aborted before the interruption. The break-off is placed after the complete prepositional phrase in which a noun phrase is later inserted. In the delayed interruption (Levelt, 1983), he inserts nahveye modiriyat (manner of management), recycles the elements produced prior to the repair and redoes the whole prepositional phrase (Fox and Jasperson, 1995). This insertion, which is a further specification, seems to be interactionally occasioned. In addressing the question posed to him earlier in the interview (not included in the transcript), he is normatively expected to produce a relevant response and to enumerate and elaborate on the root causes of economic problems as they relate to the Iranian car industry. Given this 'sequential mandate' to construct a relevant turn (Hayashi and Hayano, 2013), it seems that the action is better realized with the insertion, which is usually the case in insertion repairs (Schegloff, 2013). It is noteworthy that in this program, both the interviewer and the interviewee were generally critical of those who run the car industry. Therefore, in terms of design, the insertion suits the line of argument the guest is trying to make and better accomplishes the interactional work the turn is designed to perform (Drew et al., 2013). The retracting frames the self-repair and contextualizes it, especially given that there was not any 'hitch' in the progressive realization of the talk interrupted (Lerner and Kitzinger, 2015: 64). Retracting thus shows how self-repairs are shaped by an interplay of syntactic and interactional factors.

In terms of the action(s) accomplished, recycled turn beginnings are shown to be occasioned by the management of (potential) turn-initial overlaps (Schegloff, 1987), speakers' undecidedness about what they are going to say (Fox \& Jasperson, 1995) and the engagement of inattentive recipients (Goodwin, 1979, 1981). However, in the present study, retracting is occasioned by local interactional contingencies which arise in talk-in-interaction (Fox et al., 1996) and are not occasioned by motivations which are typical of recycled turn beginnings.

In the sections above, different self-repair operations were discussed in terms of non-lexical cutoffs, lexical devices used to index self-repairs and retracting involved in contextualizing selfrepairs. The foregoing sections have thus examined lexical initiation and retracting in isolation. The following section presents the evidence for and a discussion of the possible association between repair initiation and framing, which obviously broadens the domain of self-repair beyond the repaired segment. Given that repair operations are potentially consequential for turn 
construction especially in replacings and insertings, the section to follow provides an account of turn construction across these two self-repair operations.

\subsection{Turn Construction in Replacings and Insertings}

The published literature has already provided compelling evidence of the interrelationship between sentences in conversation and specifically syntax-for-conversation and repair (Schegloff, 1979). According to Schegloff (1979: 277), "Syntax-for-conversation and repair are both sequential organizations that bear on the production of turn-constructional units like sentences". Within this general framework of the interdependency of syntax-for-conversation and repair (e.g., Fox and Jasperson, 1995; Fox et al. 1996; Schegloff, 1979, 1987), retracting has been related to syntactic resources which co-conversationalists rely on for the contextualization or localization of self-repairs. As documented in some languages, including Finnish (Laakso and Sorjonen, 2010), insertings which are not lexically initiated, are constructed in a syntactically different fashion. In terms of syntactic turn construction, this holds for replacings as well, especially on occasions on which lexical devices do not preface the repair operation. Additionally, there is already some evidential basis suggesting that the repaired segment is interactionally significant (Jefferson, 1975; Schegloff, 1979), in that once repair is initiated and accomplished, the repairable is still significant for the interaction. This is partly due to the fact that relating the repair proper to the repairable can reveal the import of the self-repair to coparticipant(s) (Drew et al., 2013). In addition, not all traces of the repairable are excised in the repair proper (Schegloff, 1979).

The evidence coming from the current study offers further insight into a possible association between the two phases of repair initiation and repair solution. As seen in Table 1 above, Farsi does not exhibit a strong preference for lexical initiators. However, if lexical devices are not used, apart from prosodic marking which is usually associated with the candidate repair, constituent-external retracting is one resource drawn upon to frame self-repairs. As observed in Table 2 above, with lexical initiation, retracting is rarely deployed. Additionally, retracting generally occurs on occasions where repairs are not lexically initiated. In other words, non-use of lexical initiators seems to be related to retracting. Apart from 6 cases in which retracting and lexical initiation co-occur, a repair which is lexically initiated is not syntactically framed and vice versa (Table 2). Given that retracting overwhelmingly occurs on occasions on which repairs are not lexically initiated and that with lexical initiation, retracting, for the most part, does not crop up, it is possible to build a case that these two tend to be in a complementary distribution. When it comes to the choice of lexical initiation and framing, it seems that Farsi speakers adopt an either-or approach to turn design and that non-use of self-repair initiation devices triggers retracting mechanisms. Given the applicability of retracting to replacings and insertings, retracting is especially significant when the point of retraction is the beginning of the sentence (Pfeiffer, 2017), as illustrated in the following self-repairs.

ExC. 11 (\#131, REC Talk\#31,01:09)

1

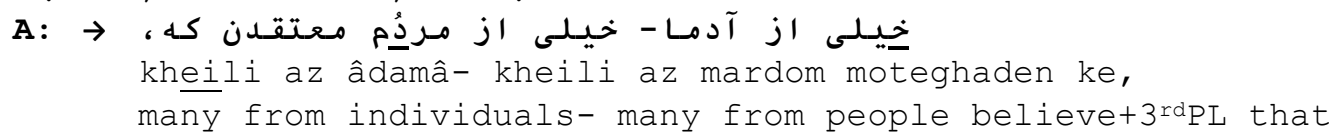


In this case, two people are talking about the skyrocketing car prices in Iran. In the replacing self-repair above, which involves retracting, speaker A is seeking B's opinion, who is a car yard owner, about the belief that those who are in car sale business are to blame for the hiking car prices. In constructing his turn, in line 1, he replaces the word âdamâ (individuals) with mardom (people). The latter word invokes consumers or ordinary people who are hardest hit by the enormous rise in prices. Given that the word in the repairable was not wrong, the 'alteration' can better realize what the speaker was in the course of saying (Schegloff, 2013). Subsequent to the replacement self-repair, which is not lexically initiated, he retracts to the beginning of the noun phrase, which coincides with the beginning of the turn and is interactionally significant (Schegloff, 1987, 2013).

The same also holds for insertings which are not lexically marked in the corpus of the study.

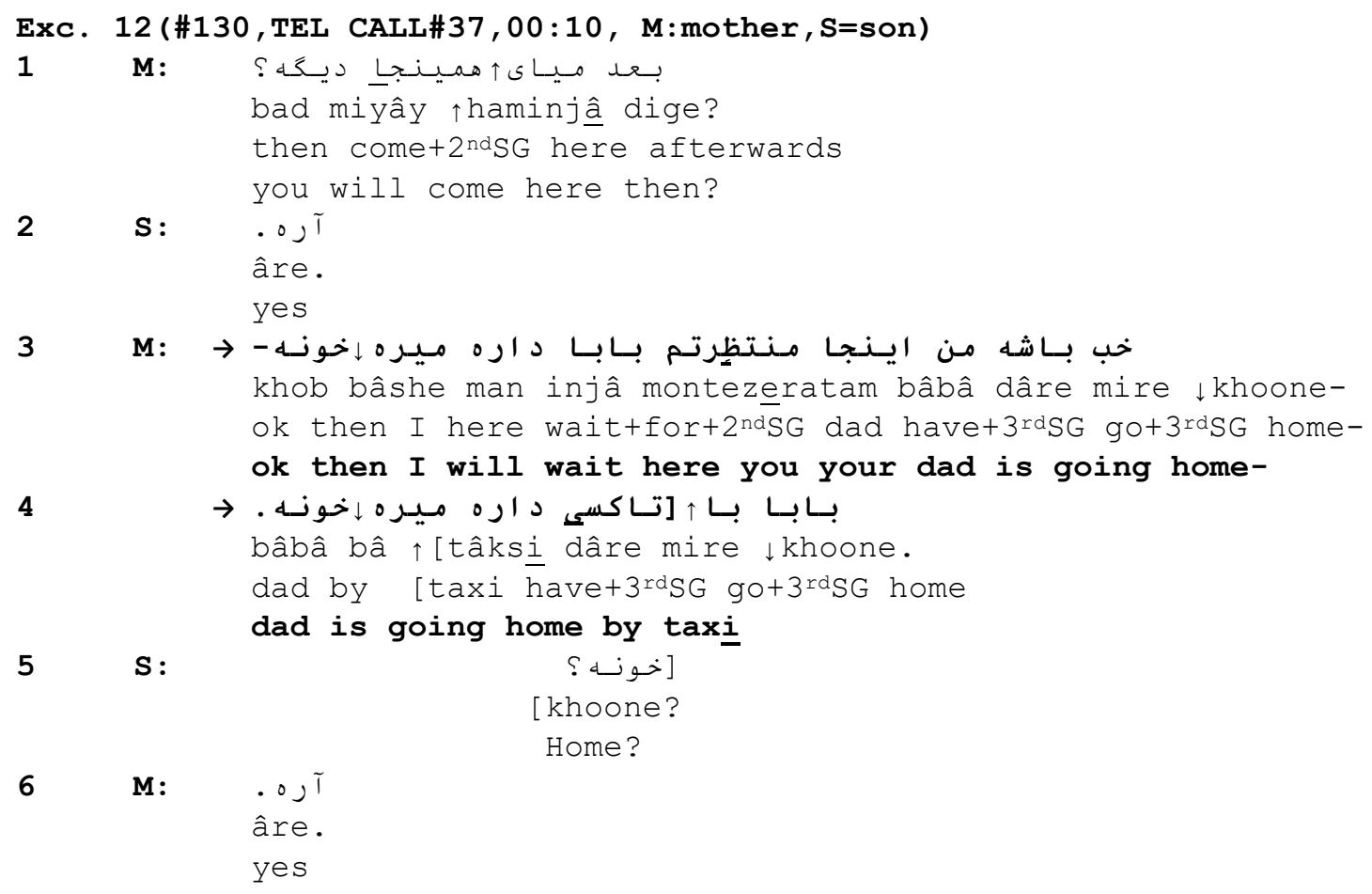


Here a mother has called her son to inform him that he is waiting for him and to inform him that the father left the car with her so the son can drive the mother home. In line 3, after informing the son, she performs an inserting self-repair, which involves telling the son that the father is going home by taxi (line 4). This is an indication of a change in their previous plan: That they were to return home by family car. The self-repair involves the insertion of bâ tâksi (by taxi) in the turn which is transition-relevant. Following that, by retracting to the beginning of the complete turn before the insertion and repeating the part after the insertion, she both preframes and postframes the self-repair (Lerner and Kitzinger, 2015). The action performed enables a shared understanding of the new plan: That the father has left the family car with the mother and is taking a taxi. It is noteworthy that the turn taken by the son in line 5 in overlap with the turn embodying the inserting self-repair, does indicate that based on their earlier plan, he did not expect to receive the information which the mother passed along.

Taken together, contingencies are pervasive in turn-constructional units in talk-in-interaction, and the architecture of self-repairs refers to systematically organized mechanisms deployed by interactants to deal with these contingencies. In so doing, speakers rely on language-internal (prosodic, lexical and more importantly syntactic) resources to indicate and manage them. Prosodic cut-off, as a common non-lexical self-repair initiator, does not necessarily yield the occurrence of self-repair; however, when it does, it exhibits some language-specific patterning in both repair initiation and repair solution. Unlike prosodic cut-off, which is postpositioned, the particle yani is routinely prepositioned and typically servers to establish a rather specific relationship between projected repair solutions and their trouble sources. In addition, whereas lexical initiators are not a frequent occurrence in Farsi, retracting is launched more frequently for framing self-repairs and is highly constrained by Farsi (morpho)syntactic rules. The preponderance of retracting on occasions of infrequency of lexical initiators, on the one hand, and infrequency of lexical initiators on occasions of retracting, on the other, provide some empirical evidence that these phenomena are related. Even if the observations were based on individual excerpts, they cumulatively produce 'the aggregate orderliness' of the self-repair phenomenon (Schegloff et al., 1977).

Repair initiation and completion seem to be organizationally related in that rules operative in one phase of the trajectory of self-repairs have some bearing on the applicability of other rules in other phases. These observations can be taken to be, at least tentatively, suggestive of the nonrandomness of the complementary distribution and infrequent co-occurrence of lexical repair initiation and repair framing, both of which are recipient-oriented (Lerner and Kitzinger, 2015) and are consequential for turn construction.

Even if the use of cut-offs or other speech perturbations, lexical initiators and retracting target different components in the trajectory of repair, they show speakers' orientation to progressivity (Lerner, 1996; Schegloff, 1979, 2007, 2013; Stivers and Robinson, 2006) and processability (Pfeiffer, 2017) and speakers' straddling the two, with skewing directed toward the latter. The final trajectory of self-repairs seems to be interactionally shaped by language-internal (morpho)syntactic and prosodic constraints and specifics. However tentative the association between lexical initiation and framing might be, it provides at least some evidential basis (far from decisive) for the possible association between repair initiation and repair solution. The possible relationship between the two can be revelatory of another way in which self-repair and 
turns in conversation or syntax-for-conversation are related. According to Schegloff (1979: 269), any aspect of the rule-governed production of talk may fail to integrate and "although many of the sources of the relevance of repair or the 'need' for it are extrinsic to syntax, the repair that is done is done in syntactic environments that, in a fashion, accommodate it". The distribution of lexical devices and retracting provides further evidence that syntax-for-conversation and selfrepairs are operative in the same sequential environment.

\section{Concluding Remarks}

Documenting repair initiation and framing in Farsi, this study furthers our understanding of the topic of self-repair by plotting the trajectory of self-repairs from their initiation to their solution, grounded in the situated conduct of co-conversationalists in spontaneous interaction. It examines two components of the sequentially consequential architecture of self-repair and explores a range of inter-related phenomena involved in repair initiation and accomplishment. The findings shed light on how courses of action related to locating and signaling troubles of speaking and attempting self-repairs are launched. This provides empirical evidence into how solutions to generic interactional problems are fashioned out of the linguistic resources of Farsi and the consequentiality of Farsi semiotic structures for social interaction. While not ruling out the role of other semiotic resources in the organization of self-repairs (Selting, 1996), the findings suggest that participants in interaction rely on various resources such as speech perturbations, lexical devices and syntactic resources to secure intersubjective understanding. They draw upon local language-specific resources to shape solutions to generic interactional contingencies as they arise in ordinary interaction. Yani-prefaced repairs document a solution to the problem of 'contiguity breaks' (Sidnell, 2013) which occur in the turn-in-progress and represent a technique used to convey to the interlocutor how the current turn is to be understood in relation to what has occurred prior to it. The findings reveal an organization operative in different phases of selfrepair, which suggests the orderliness of 'initiator techniques' and framing (Schegloff et al. 1977) and provide preliminary evidence that the complementary distribution of lexical initiation and retracting seems to have a systematic base.

The analysis presented shows the relevance of syntax-for-conversation to the production of conversational turns and that of organization of self-repair to the occasions on which troubles arise (Fox et al., 1996; Schegloff, 1979). It also indicates that in the trajectory of repairs, different components work alongside each other to ensure both the processability and progressivity of speech (Lerner, 1996; Pfeiffer, 2017; Schegloff, 1979, 2007, 2013). This suggests an analytic shift in undertakings concerning the role of (morpho)syntactic or lexical variables in self-repair initiation and accomplishment. The variations exhibited in self-repair practices in Farsi talk-in-interaction could be attributed to the mobilization of different local resources of the language, different 'social formations' and different conversational practices (Sidnell, 2007), the full explication of which invites separate treatment. Even if the findings are preliminary, it is hoped that they contribute to the by-now extensive literature on the interplay between repair and syntax-for-conversation. While there is already compelling evidence of the mutual relationship between the two (Fox and Jasperson, 1995; Fox et al., 1996; Schegloff, 1979, 1987), particularizing the relationship between lexical initiation and retracting would be worthwhile, awaiting future research. 


\section{References}

Anvari, H., 1988. Dastoor Zabâne Fârsi [Farsi Grammar]. Tehran: Payame Noor Publication.

Atkinson, J. M., \& Heritage, J., 1999. Transcript notation-Structures of social action: studies in conversation analysis. Aphasiology, 13(4-5), 243-249.

Berg, Thomas, 1986. The aftermath of error occurrence: psycholinguistic evidence of cut-offs. Language and Communication 6, 195-213.

Birkner, K., Henricson, S., Lindholm, C., \& Pfeiffer, M., 2012. Grammar and self-repair: Retraction patterns in German and Swedish prepositional phrases. Journal of Pragmatics, 44(11), 1413-1433.

Blackmer, E. R., \& Mitton, J. L., 1991. Theories of monitoring and the timing of repairs in spontaneous speech. Cognition, 39, 173-194.

Bredart, Serge, 1991. Word interruption in self-repairing. Journal of Psycholinguistic Research 20, 123-138.

Comrie, Bernard, Haspelmath, Martin \& Bickel, Balthasar, 2015. The Leipzig Rules:

Conventions for Interlinear Morpheme-by-Morpheme Glosses. Leipzig: Max Planck Institute for Evolutionary Anthropology.

Cutler, A., 1983. Speakers' conceptions of the function of prosody. In: Cutler, A. \& Ladd, D. R. (Eds.), Prosody: Models and Measurements. Springer, Verlag, Berlin, pp. 79-92.

Dabir Moghaddam, M., 2013. Radeshenasiye Zabanhaye Irani [Typology of Iranian Languages]. Tehran: SAMT Publications.

Drew, P., Walker, T., \& Ogden, R. 2013. Self-repair and action construction. In: Hayashi, M., Raymond, G., \& Sidnell, J. (Eds.), Conversational repair and human understanding (No. 30). Cambridge, University Press Cambridge, pp. 71-94.

Egbert, M. M., 1996. Context-sensitivity in conversation: Eye gaze and the German repair initiator bitte?. Language in Society, 25(4), 587-612.

Egbert, M. M., 2002. Der Reparatur-Mechanismus in deutschen und interkulturellen Gespra chen. [The Repair Mechanism in German and Intercultural Conversation]. Habilitation, Universita“t Oldenburg.

Egbert, M., 2004. Other-initiated repair and membership categorization-some conversational events that trigger linguistic and regional membership categorization. Journal of Pragmatics, 36(8), 1467-1498.

Fincke, Steven, 1999. The syntactic organization of repair in Bikol. In: Fox, B., Jurafsky, D., \& Michaelis, L. (Eds.), Cognition and Function in Language. CSLI, Stanford, pp. 252-267. 
Fox, B. A., Benjamin, T., \& Mazeland, H., 2013. Conversation analysis and repair organization: Overview. In Chapelle, C. A. (Ed.), The Encyclopedia of Applied Linguistics, Wiley-Blackwell, Oxford, U.K., pp. 1094-1097.

Fox, Barbara, Hayashi, Makoto, Jasperson, Robert, 1996. Resources and repair, a cross-linguistic study of syntax and repair. In: Ochs, E., Schegloff, E.A., Thompson, S. (Eds.), Interaction and Grammar. Cambridge University Press, Cambridge, pp. 185-237.

Fox, B. A., \& Jasperson, R., 1995. A syntactic exploration of repair in English conversation. In: Davis, P. (Ed.), Descriptive and theoretical modes in the alternative linguistics, John Benjamins, Amsterdam, pp. 77-134.

Fox, Barbara, Wouk, Fay, Hayashi, Makoto, Fincke, Steven, Tao, Liang, Sorjonen, Marja-Leena, Laakso, Minna, Hernandez Wilfrido Flores, 2009. A cross linguistic investigation of the site of initiation in same-turn self-repair. In: Sidnell, J. (Ed.), Conversation Analysis: Comparative Perspectives. Cambridge University Press, Cambridge, pp. 60-103.

Fox, Barbara, Maschler, Yael, Uhmann, Susanne, 2010. A cross-linguistic study of self-repair: evidence from English, German and Hebrew. Pragmatics 42, 2487-2505.

Fox, Barbara A., Wouk, Fay, Fincke, Steven, Flores, Wilfredo Hernandez, Hayashi, Makoto, Laakso, Minna, Maschler, Yael, Mehrabi, Abolghasem, Sorjonen, Marja-Leena, Uhmann, Susanne \& Yang, Hyun Jung, 2017. Morphological self-repair: Self-repair within the word. Studies in Language 41(3): 638-659.

Goodwin, C., 1979. The interactive construction of a sentence in natural conversation. In: Psathas, G. (Ed.). Everyday language: Studies in ethnomethodology. Irvington, New York, pp. $97-121$.

Goodwin, C., 1981. Conversational organization: Interaction between speakers and hearers. Academic Press, New York.

Goodwin C., 1996. Transparent Vision. In: Ochs, E., Schegloff, E. A. \& Thompson, S. A. (Eds.). Interaction and Grammar. Cambridge University Press, New York, pp. 370-404.

Hayashi, Makoto, 1994. A comparative study of self-repair in English and Japanese conversation. In: Akatsuka, N. (Ed.), Japanese/Korean Linguistics IV. CSLI, Stanford, pp. 77-93.

Hayashi, M., \& Hayano, K., 2013. Proffering insertable elements: a study of other-initiated repair in Japanese. Conversational repair and human understanding, 30, 293. In: Hayashi, M., Raymond, G., \& Sidnell, J. (Eds.), Conversational repair and human understanding (No. 30). Cambridge University Press, Cambridge, pp. 293-321.

Hayashi, M., Raymond, G., \& Sidnell, J., 2013. Conversational repair and human understanding: an introduction. In: Hayashi, M., Raymond, G., \& Sidnell, J. (Eds.), Conversational repair and human understanding (No. 30), Cambridge University Press, Cambridge pp. 41-70. 
Jasperson, Robert, 1998. Repair after cut-off: explorations in the grammar of focused repair of the turn-constructional unit-so-far. Unpublished Ph. D. thesis. Department of Linguistics, University of Colorado.

Jasperson, Robert, 2002. Some linguistic aspects of closure cut-off. In: Ford, C. E., Fox, B. A., \& Thompson, S. A. (Eds.), The Language of Turn and Sequence. Oxford University Press, Oxford, pp. 257-286.

Jefferson, Gail, 1975. Error Correction as an Interactional Resource. Language in Society 3, 181199.

Jefferson, Gail, 1987. On exposed and embedded correction in conversation. In Button, G. \& Lee, J. R. E. (Eds.), Talk and social organization. Multilingual Matters, Clevedon, UK:. pp. 86100.

Karkkainen, Elise, Sorjonen, Marja-Leena, Helasvuo, Marja-Liisa, 2007. Discourse structure. In: Shopen, T. (Ed.), Language Typology and Syntactic Description. Second edition. Cambridge University Press, Cambridge, pp. 301-371.

Kazemi, A., 2006. A Systematic Study of Self-Repairs in Second Language Classroom Presentations: with Some Reference to Social Variables and Language Proficiency. Unpublished $\mathrm{Ph}$. D. Dissertation. University of New South Wales, Australia.

Laakso, M., \& Sorjonen, M-L., 2010. Cut-off or particle-Devices for initiating self-repair in conversation. Pragmatics, 42(4), 1151-1172.

Lerner, Gene H., 1996. On the 'semi-permeable' character of grammatical units in conversation: Conditional entry into the turn space of another speaker. In: Ochs, E., Schegloff, E. A., \& Thompson, S. A. (Eds.), Interaction and Grammar. Cambridge University Press, Cambridge, pp. 238-276.

Lerner, G. H., \& Kitzinger, C., 2010, July. Repair prefacing: Preparing the way for same-turn self-repair. Paper presented to the International Conference for Conversation Analysis, Mannheim, Germany.

Lerner, G. H., 2013. On the place of hesitating in delicate formulations: a turn-constructional infrastructure for collaborative indiscretion. In: Hayashi, M., Raymond, G., \& Sidnell, J. (Eds.), Conversational repair and human understanding (No. 30). Cambridge University Press, Cambridge, pp. 95-134.

Lerner, G. H., \& Kitzinger, C., 2015. Or-prefacing in the organization of self-initiated repair. Research on Language and Social Interaction, 48(1), 58-78.

Lerner, G. H., \& Kitzinger, C., 2019. Well-prefacing in the organization of self-initiated repair. Research on Language and Social Interaction, 52(1), 1-19.

Levelt, W. J., 1983. Monitoring and self-repair in speech. Cognition, 14(1), 41-104.

Levelt, W. J., \& Cutler, A., 1983. Prosodic marking in speech repair. Semantics, 2(2), 205-218. 
Levinson, S. C., 1983. Pragmatics. Cambridge University Press, Cambridge.

Local, John, 1992. Continuing and restarting. In: Auer, P., di Luzio, A. (Eds.), The Contextualization of Language. John Benjamins, Amsterdam, pp. 273-296.

Mirzayan, A., 2008. A preliminary study of same-turn self-repair initiation in Wichita conversation. In: Harrison, D., Rood D. \& Dwyer, A. (Eds.), Lessons from documented endangered languages. John Benjamins, Amsterdam, pp. 317-354.

Nakatani, C., \& Hirschberg, J., 1993. A speech-first model for repair detection and correction. Proceedings of the Association of Computational Linguistics: 46-53.

Németh, Z., 2012. Recycling and replacement repairs as self-initiated same-turn self-repair strategies in Hungarian. Pragmatics, 44(14), 2022-2034.

Ogden, R., 2001. Turn transition, creak and glottal stop in Finnish talk-in-interaction. Journal of the International Phonetic Association, 31(1), 139-152.

Pfeiffer, M., 2014. Formal vs. functional motivations for the structure of self-repair in German. In: MacWhinney, B., Malchukov, A., \& Moravcsik, E. (Eds.), Competing Motivations in Grammar and Usage. Oxford University Press, Oxford, pp. 229-245.

Pfeiffer, M., 2017. The syntax of self-repair in German: An explanatory model. Pragmatics, 119, 63-80.

Rieger, Caroline L., 2003. Repetitions as self-repair strategies in English and German conversations. Pragmatics 35, 47-69.

Sadat-Tehrani, N., 2009. The alignment of $\mathrm{L}+\mathrm{H}^{*}$ pitch accents in Persian intonation. Journal of the International Phonetic Association, 39(2), 205-230.

Sadri, G., Hakami, N., \& Hakami, N., 2002. Farhange moâsere Fârsi [Farsi Contemporary Dictionary]. Farhang-e Moaser Publication, Tehran.

Schegloff, Emanuel A., 1979. The relevance of repair to syntax-for-conversation. In: Givo'n, T. (Ed.), Discourse and Syntax. Syntax and Semantics 12. Academic Press, New York, pp. 261-286.

Schegloff, Emanuel A., 1982. Discourse as an interactional achievement: some uses of "uh huh" and other things that come between sentences. In: Tannen, D. (Ed.) Georgetown University Roundtable on Languages and Linguistics. Georgetown University Press, Washington DC. pp. 71-93.

Schegloff, E. A., 1984. On some gestures relation to talk. In J. Atkinson and J. Heritage (eds.), Structures of social action. Cambridge University Press, Cambridge, pp. 266-297.

Schegloff E. A., 1987. Recycled turn beginnings: a precise repair mechanism in conversation's turn-taking organisation. In: Button, G. \& Lee, J. R. E. (Eds.) Talk and Social Organisation. Multilingual Matters, Philadelphia, pp. 70-93. 
Schegloff, Emanuel A., 2003. The surfacing of the suppressed. In: Glenn, P., LeBaron, C. \& Mandelbaum, J. (Eds.), Studies in Language and Social Interaction: A Festschrift in Honor of Robert Hopper. Lawrence Erlbaum Associates, Mahwah, NJ., pp. 241-262.

Schegloff, E. A., 2006. Interaction: The Infrastructure for Social Institutions, the Natural Ecological Niche for Language, and the Arena in which Culture is Enacted. In: Enfield, N. J. and Levinson, S. C. (Eds.), Roots of Human Sociality: Culture, Cognition and Interaction. Berg, Oxford, pp. 70-96.

Schegloff, E. A., 2007. Sequence Organization in Interaction. A Primer in Conversation Analysis I. Cambridge University Press, Cambridge.

Schegloff, E. A., 2013. Ten operations in self-initiated, same-turn repair. In: Hayashi, M., Raymond, G., \& Sidnell, J. (Eds.), Conversational repair and human understanding (No. 30). Cambridge University Press, Cambridge, pp. 41-70.

Schegloff, Emanuel A., Jefferson, Gail, \& Sacks, Harvey, 1977. The preference for selfcorrection in the organization of repair in conversation. Language 53, 361-382.

Selting, M., (1996). On the interplay of syntax and prosody in the constitution of turnconstructional units and turns in conversation. Pragmatics 6(3), 371-388.

Sidnell, Jack, 2007. Comparative studies in conversation analysis. Annual Review of Anthropology 36, 229-244.

Sidnell, Jack, 2009. Comparative perspectives in conversation analysis. In: Sidnell, J. (Ed.), Conversation Analysis: Comparative Perspectives. Cambridge University Press, Cambridge, pp. 3-27.

Sparks, R. B., 1994. The structure of self-repair in English conversation (natural language discourse). Unpublished Doctoral dissertation, University of Colorado.

Stivers, Tanya \& Robinson, \& Jeffrey D., 2006. A preference for progressivity in interaction. Lang. Soc. 35, 367-392.

Uhmann, Susanne, 2001. Some arguments for the relevance of syntax to same-sentence selfrepair in everyday German conversation. In: Selting, M., Couper-Kuhlen, E. (Eds.), Studies in Interactional Linguistics. John Benjamins, Amsterdam, pp. 373-404.

Wouk, Fay, 2005. The syntax of repair in Indonesian. Discourse Studies 7, 237-258.

Zahn, C. J., 1984. A reexamination of conversational repair. Communications Monographs, 51(1), 56-66.

\section{Appendix}

\begin{tabular}{|l|l|l|l|l|c|}
\hline \multicolumn{2}{|c|}{ REPLACINGS } & \multicolumn{2}{c|}{ ABORTINGS } \\
\hline Lexical Initiator & Meaning & f & Lexical Initiator & Meaning & f \\
\hline
\end{tabular}




\begin{tabular}{|c|c|c|c|c|c|}
\hline migam & I mean & 1 & migam & I mean & 1 \\
\hline negation words & not & 2 & masalan & for example & 2 \\
\hline dar vâghe (haghighat) & in fact & 6 & hâlâ & anyway & 3 \\
\hline mishe goft & one can say & 1 & dar haghighat & in fact & 1 \\
\hline eslâh mikonam & I correct myself & 1 & albatte ino ham begam & let me add this & 1 \\
\hline$y \hat{a}$ & or & 2 & & & \\
\hline hâlâ & anyway & 3 & & & \\
\hline masalan & for example & 1 & & & \\
\hline che arz konam & how can I put it & 1 & & & \\
\hline chiz & placeholder filler & 1 & & & \\
\hline
\end{tabular}

